\title{
Applicability of current staging/categorization of $\alpha$-synuclein pathology and their clinical relevance
}

\author{
Laura Parkkinen · Tuula Pirttilä • Irina Alafuzoff
}

Received: 1 December 2007 / Revised: 30 January 2008 / Accepted: 30 January 2008 / Published online: 23 February 2008 (C) Springer-Verlag 2008

\begin{abstract}
In Parkinson's disease (PD) and dementia with Lewy bodies (DLB) $\alpha$-synuclein $(\alpha S)$ pathology is seen that displays a predictable topographic distribution. There are two staging/categorization systems, i.e. Braak's and McKeith's, currently in use for the assessment of $\alpha \mathrm{S}$ pathology. The aim of these diagnostic strategies in pathology is, in addition to assess the stage/severity of pathology, to assess the probabilities of the related clinical symptomatology i.e. dementia and extrapyramidal symptoms (EPS). Herein, we assessed the applicability of these two staging/categorization systems and the frequency of dementia and EPS in a cohort of $226 \alpha \mathrm{S}$-positive-subjects. These subject were selected from a large autopsy sample $(n=1,720)$, irrespective of the clinical presentation, based on the detection of $\alpha \mathrm{S}$-immunoreactivity (IR) in one of the most vulnerable nuclei; in the dorsal motor nucleus of vagus, substantia nigra and basal forebrain. The frequency of $\alpha \mathrm{S}$-IR lesions in this large cohort was $14 \%$ (248 out of 1,720). If applicable, each of the 226 subjects with all required material
\end{abstract}

L. Parkkinen · I. Alafuzoff $(\square)$

Department of Clinical Medicine, Unit of Neurology,

Section of Neuropathology, Kuopio University,

Yliopistonranta 1 C, P.O. Box 1627, 70211 Kuopio, Finland

e-mail: irina.alafuzoff@uku.fi; Irina.Alafuzoff@uku.fi

\section{T. Pirttilä}

Department of Clinical Medicine, Unit of Neurology,

Kuopio University, Yliopistonranta $1 \mathrm{C}$,

P.O. Box 1627, 70211 Kuopio, Finland

T. Pirttilä

Department of Neurology,

Kuopio University Hospital, Kuopio, Finland

I. Alafuzoff

Department of Pathology,

Kuopio University Hospital, Kuopio, Finland available was assigned a neuropathological stage/category of PD/DLB and finally the neuropathological data was analyzed in relation to dementia and EPS. $83 \%$ of subjects showed a distribution pattern of $\alpha \mathrm{S}$-IR that was compatible with the current staging/categorization systems. Around $55 \%$ of subjects with widespread $\alpha \mathrm{S}$ pathology (Braak's PD stages 5-6) lacked clinical signs of dementia or EPS. Similarly, in respect to those subjects that fulfilled the McKeith criteria for diffuse neocortical category and displaying only mild concomitant Alzheimer's disease-related pathology, only $48 \%$ were demented and $54 \%$ displayed EPS. It is noteworthy that some subjects $(17 \%)$ deviated from the suggested caudo-rostral propagation suggesting alternative routes of progression, perhaps due to concomitant diseases and genetic predisposition. In conclusion, our results do indeed confirm that current staging/categorization systems can readily be applied to most of the subjects with $\alpha \mathrm{S}$ pathology. However, finding that around half of the subjects with abundant $\alpha \mathrm{S}$ pathology remain neurologically intact is intriguing and raises the question whether we do assess the actual disease process.

Keywords Dementia - Extrapyramidal symptoms · Lewy body dementia $\cdot$ Parkinson disease $\cdot \alpha$-Synuclein

\section{Introduction}

There are two staging/categorization systems commonly in use for the assessment of the progressive regional distribution of the pathology seen in Parkinson's disease (PD) and dementia with Lewy bodies (DLB). Both of these staging/ categorization systems are based on the assessment of misfolded $\alpha$-synuclein $(\alpha \mathrm{S})$ protein within selectively vulnerable neuronal populations which is considered to be either 
directly responsible or at least intimately linked to the neuronal dysfunction seen in PD and DLB. In this respect, $\alpha \mathrm{S}$ immunoreactive (IR)-inclusions in the brainstem have been claimed to be responsible for the extrapyramidal symptoms (EPS), whereas dementia has been attributed to the limbic and neocortical spread of these lesions. Thus, PD and DLB are thought to form a clinico-pathologic continuum wherein the clinical manifestation of EPS and/or dementia depends on the anatomical distribution and the load of $\alpha \mathrm{S}$ pathology $[4,17,19,25,28,30]$.

In 2003, Braak and colleagues reported that the $\alpha \mathrm{S}$ pathology begins in clearly defined induction sites and advances, not in a random, but in a predictable sequence with increasing severity throughout the brain $[4,11]$. Based on the analysis of the regional distribution of $\alpha$ S-IR inclusions in a cohort including both neurologically unimpaired subjects and patients with PD, a staging system was devised whereby $\alpha \mathrm{S}$ pathology was divided into six successive stages. In the central nervous system, the proposed sequence begins in the dorsal motor nucleus of vagus $(\mathrm{dmV})$, and then proceeds with an upward progression via locus coeruleus (LC) (stage 2) to the substantia nigra (SN) (stage 3), and then to the basal foreberain (BFB) and transentorhinal region (stage 4) until it finally reaches the neocortex (stages 5-6).

Already in 1996, the consortium on DLB international workshop proposed their consensus guidelines for the clinical and pathologic diagnosis of DLB [27] that later, in 2005 were somewhat revised [28]. These consensus criteria of DLB subdivide subjects into three different neuropathological categories; brainstem predominant, limbic/transitional and diffuse neocortical depending on the anatomical distribution of the $\alpha \mathrm{S}$-IR structures [28]. These criteria also include the semiquantitative grading of lesion density, although the pattern of regional involvement has been assumed to be more important than the actual count of inclusions. It is noteworthy that in the revised recommendations by McKeith et al from 2005 [28], it is emphasized that the concomitant pathologies should be taken into account when assessing the causative relationships between pathologies and symptoms. Thus, the most common pathology seen in aged demented individuals, i.e. Alzheimer's disease (AD)-related pathology, should be evaluated while assessing the likelihood of causation, i.e. that the $\alpha \mathrm{S}$ pathology is associated with a DLB clinical syndrome.

Herein, we assess the applicability of these two current staging/categorization systems of synucleinopathies in a large autopsy material collected, not on the basis of clinical presentation, but by $\alpha \mathrm{S}$ immunoreactivity in some of the most vulnerable nuclei; $\mathrm{dmV}, \mathrm{SN}$ and $\mathrm{BFB}$. Thus, the selection of material was entirely based on the presence of $\alpha \mathrm{S}$ pathology irrespective of clinical phenotype. All subjects, if applicable, were assigned a stage following in detail Braak staging recommendations and a McKeith neuropathological category following in detail recommendations by the consortium on DLB international workshop $[4,28]$. The frequency of dementia and EPS was assessed in each stage and the likelihood that dementia was due to AD-related pathology or $\alpha \mathrm{S}$ pathology was also examined.

\section{Materials and methods}

Selection of subjects and the clinical assessment

The flowchart delineates the logistics of this study (Fig. 1). A total of 1,720 elderly individuals (age at death $>40$ years) that had undergone an autopsy together with an examination of the brain during the years 1996-2005 in the Kuopio University Hospital were included in this study. From this large autopsy sample, we selected $248(14 \%)$ subjects that displayed $\alpha \mathrm{S}$-IR structures in the SN and/or BFB nuclei: nucleus basalis of Meynert (nbM) and amygdaloid complex (AC). Screening of $\mathrm{dmV}$ was also carried out in 1996-2000 and revealed that in 24 subjects out of $904(3 \%) \alpha$ S-IRstructures were restricted to the lower brain stem nuclei ( $\mathrm{dmV}$ and/or LC) [33]. Five subjects were excluded from the analysis because they had received a pathological diagnosis of MSA. Seventeen subjects were excluded due to lack of clinical information or inadequate amount of brain material required for the classification as recommended by Mc Keith and Braak [4, 28], and thus ultimately, this study examined 226 subjects.

The diagnosis of dementia was based on the DSM-III criteria and the criteria of the National Institute of Neurological and Communicative Disorders and StrokeAlzheimer's Disease and Related Disorders Association (NINCDS-ADRDA) [29]. The diagnosis of PD followed the criteria established by the United Kingdom Parkinson's Disease Society Brain Bank whereby PD was considered present if the patient had at least two of the four cardinal symptoms (resting tremor, rigidity, hypokinesia and postural instability) and exhibited a positive response to levodopa [9]. The initial screening for both dementia and EPS had taken place in a primary health care centre. With respects to dementia, all patients scoring 26 or less in minimental State Examination (MMSE) had been referred to a neurologist for further evaluation and all patients scoring $>26$ in MMSE but displaying signs of memory impairment had been referred to a CERAD test. Consequently, many subjects had been examined by a neurologist and all had at least visited a general physician (within a maximum of 1 year before death). It is noteworthy that many of the subjects included in this study had been under continuous clinical follow-up due to some chronic disease. Admittedly, some subjects may have developed subtle extrapyramidal 
Fig. 1 The flowchart delineating the logistics of this study. a The $\alpha \mathrm{S}$-immunoreactive inclusions were screened in substantia nigra, amygdaloid complex and dorsal motor nucleus of vagus. b Schematic presentation of both Braak staging and McKeith categorization $[4,28]$ and c schematic presentation of assessment of likelihood that $\alpha \mathrm{S}$-immunoreactive inclusion are associated with dementia with Lewy bodies [28] a) Screening of $\alpha \mathrm{S}$ immunoreactivity in the $\mathrm{SN}, \mathrm{nbM}$ and $\mathrm{AC}$ and $\mathrm{dmV}$ in $\mathbf{1 7 2 0}$ subjects (age at death \pm 40 years) that underwent an autopsy during the years 1996-2005 in the Kuopio University hospital

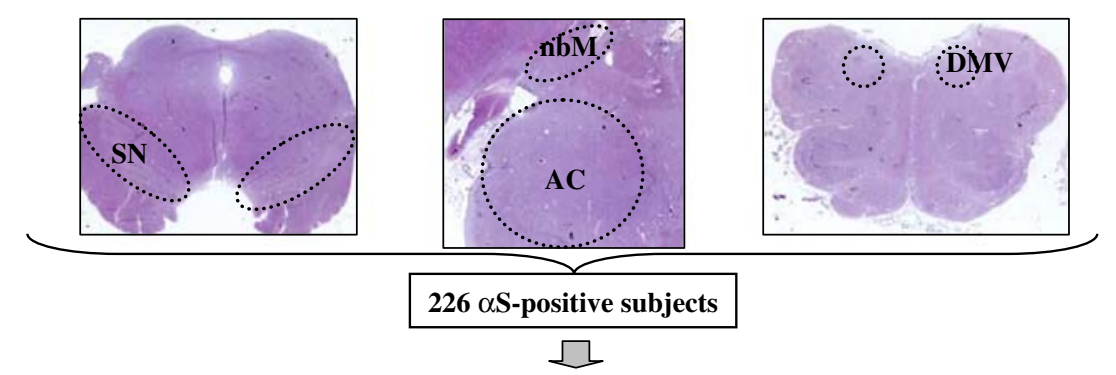

b) To assign the Braak stage and the McKeith neuropathological category of Parkinson's disease related pathology, $\alpha \mathrm{S}$ immunohistochemistry was carried out on all 10 sections listed below. Both assignments are based on semiquantitative assessment and regional distribution of $\alpha \mathrm{S}$-immunoreactive structures.

\begin{tabular}{|c|c|c|c|c|c|c|c|c|c|c|}
\hline \multirow[t]{2}{*}{ Section } & \multirow[t]{2}{*}{ Anatomical region } & \multicolumn{6}{|c|}{ Braak stage } & \multicolumn{3}{|c|}{ McKeith category } \\
\hline & & 1 & 2 & 3 & 4 & 5 & 6 & I & II & III \\
\hline 1. medulla & $\begin{array}{l}\text { dorsal motor } \\
\text { nucleus of vagus }\end{array}$ & $+/++$ & $+/++$ & +/++/+++ & $++/+++$ & $++/+++$ & +++ & $1-3$ & $1-3$ & $1-3$ \\
\hline \multirow[t]{2}{*}{ 2. pons } & locus coeruleus & $\mathbf{0}$ & + & $+/ /++/+++$ & $++/+++$ & $++/+++$ & $++/+++$ & $1-3$ & $1-3$ & $1-3$ \\
\hline & Raphe nucleus & $\mathbf{0}$ & + & $+/++$ & $+/++/+++$ & $++/+++$ & $++/+++$ & & & \\
\hline 3. midbrain & substantia nigra & $\mathbf{0}$ & $\mathbf{0}$ & $+/++/+++$ & $++/+++$ & $++/+++$ & +++ & $1-3$ & $1-3$ & $1-3$ \\
\hline \multirow[t]{3}{*}{ 4. basal forebrain } & $\begin{array}{l}\text { nucleus basalisof } \\
\text { Meynert }\end{array}$ & $\mathbf{0}$ & 0 & $+/++/+++$ & $+/++/+++$ & $++/+++$ & +++ & $0-2$ & $2-3$ & $2-3$ \\
\hline & $\begin{array}{l}\text { amygdaloid } \\
\text { complex }\end{array}$ & o & o & IR & IR & IR & IR & $0-2$ & $2-3$ & $3-4$ \\
\hline & $\begin{array}{l}\text { (trans)entorhinal } \\
\text { cortex }\end{array}$ & o & 0 & o & $+/++$ & ++ & $++/+++$ & $0-1$ & $1-3$ & $2-4$ \\
\hline \multirow[t]{2}{*}{ 5. hippocampus } & CA2 region & $\mathbf{0}$ & $\mathbf{0}$ & + & $+/++$ & $+/++/+++$ & $++/+++$ & & & \\
\hline & $\begin{array}{l}\text { temporo-occipital } \\
\text { gyrus }\end{array}$ & 0 & o & o & $+/++$ & ++ & $++/+++$ & & & \\
\hline 6. insular cortex & & $\mathbf{0}$ & 0 & 0 & 0 & + & ++ & & & \\
\hline 7. cingulate gyrus & & $\mathbf{0}$ & $\mathbf{0}$ & $\mathbf{0}$ & 0 & + & ++ & $0-1$ & $1-3$ & $2-4$ \\
\hline 8. temporal gyrus & & 0 & 0 & 0 & 0 & + & ++ & 0 & $0-2$ & $2-3$ \\
\hline 9. frontal cortex & & 0 & 0 & 0 & 0 & $\mathbf{0}$ & + & 0 & $0-1$ & $1-3$ \\
\hline 10. parietal cortex & & 0 & 0 & 0 & 0 & $\mathbf{0}$ & + & 0 & 0 & $0-2$ \\
\hline
\end{tabular}

c) In order to assess the likelihood that the $\alpha$ S-immunoreactive lesions are associated with a DLB clinical syndrome, Alzheimer's Disease related neurofibrillary pathology was assessed using AT8 IHC and staged as recommended by Braak

\begin{tabular}{|c|c|c|c|}
\hline \multirow{2}{*}{$\begin{array}{c}\text { Category of } \\
\text { Lewy body type pathology }\end{array}$} & Braak stage 0-II & Braak stage III-IV & Braak stage V-VI \\
\cline { 2 - 4 } & Low & Low & Low \\
\hline Brainstem predominant & High & Intermediate & Low \\
\hline Limbic transitional & High & High & Intermediate \\
\hline Diffuse neocortical & \multicolumn{2}{|c|}{} \\
\hline
\end{tabular}

signs or mild cognitive impairment between the last clinical examination and death, but it is most unlikely that the presence of moderate or full-blown parkinsonian syndrome/ dementia would have been overlooked.

\section{Neuropathological assessment}

According to the dissection protocol used in the Kuopio University Hospital, the brains were weighed, evaluated for grossly detectable lesions and vessel abnormalities, perfused with and immersed in $10 \%$ buffered formalin for at least one week and cut in coronal slices of $1 \mathrm{~cm}$ thickness. Brain specimens were embedded in paraffin and cut into
$7 \mu$ m-thick sections. Immohistochemical (IHC) methodology was used to visualize the expression of $\alpha \mathrm{S}$ and hyperphosphorylated $\tau(\mathrm{HP} \tau)$. The sections were deparaffinized and rehydrated according to a routine procedure. For $\alpha \mathrm{S}$ IHC, the sections were autoclaved $\left(120^{\circ} \mathrm{C}\right)$ in citrate buffer for $10 \mathrm{~min}$ and pretreated with $80 \%$ formic acid at room temperature for $5 \mathrm{~min}$. Monoclonal antibodies to human $\alpha \mathrm{S}_{1-140}$ (Novocastra, Newcastle upon Tyne, UK) at a dilution of $1: 1,000$ and to human $\operatorname{HP} \tau$ at a dilution of $1: 500$ (Innogenetics, Ghent, Belgium) were applied. For detection, Histostain SP kit (Zymed, San Francisco, CA) was used with Romulin AEC chromogen (Biocare Medical, Walnut Creek, CA). The expression of $\alpha \mathrm{S}$ was assessed in 
10 brain regions: (1) medulla with $\mathrm{dmV}$; (2) pons with $\mathrm{LC}$ and raphe nucleus (RN); (3) midbrain with $\mathrm{SN}$; (4) BFB including $\mathrm{nbM}, \mathrm{AC}$, and transentorhinal cortex; (5) posterior hippocampus at the level of geniculate nucleus including the CA2 region of the hippocampus and temporo-occipital gyrus; (6) insular cortex; (7) anterior cingulate gyrus; (8) superior temporal gyrus (Broadman area 22); (9) frontal cortex (Broadman area and (10) parietal cortex (Broadman areas 39, 40). The selection of regions was based on the currently used staging systems [4, 28] (See Fig. 1). HP $\tau$ IHC was carried out on sections from hippocampus, temporal and occipital cortices and the regional distribution of AD-related neurofibrillary pathology was subdivided into 6 stages (I-VI) as has been described previously [6].

The number of $\alpha \mathrm{S}$-IR inclusions was counted within the microscopic field at $\times 200$ magnification (diameter of $1 \mathrm{~mm}$ ) and assessed semiquantitatively in all brain areas examined. The total thickness of the cortical grey matter and AC were assessed according to the established pathological guidelines [28] and rated as follows: $1=$ mild (sparse inclusions at $\times 100) ; 2=$ moderate $(>1$ inclusion in low power field at $\times 200$ magnification); $3=$ severe $(\geq 4$ inclusions in low power field at $\times 200$ magnification); $4=$ very severe (numerous inclusions). In the nbM and all subcortical regions, $\alpha$ S-IR inclusions were counted unilaterally within entire nuclei and assessed following an arbitrary grading system: in $\mathrm{nbM}$ and $\mathrm{SN},+=$ mild ( $<25$ inclusions); ++ = moderate $(25-50$ inclusions); $+++=$ severe $(>50$ inclusions), in $\mathrm{LC}$ and $\mathrm{dmV},+=$ mild ( $1-2$ inclusions); $++=$ moderate $(2-10$ inclusion $),+++=$ severe $(>10$ inclusions). Several inclusions within one neuron were counted as a single inclusion. The $\alpha \mathrm{S}$-IR structures were designated as being present $(+)$ or not $(0)$ in raphe nucleus and CA2 region of the hippocampus. If no $\alpha \mathrm{S}-\mathrm{IR}$ inclusions were identified in the sections of medulla, pons, midbrain or BFB, the result was verified in at least 3-4 consecutive sections i.e. the subsequent 5 th, 10th, 15 th and 20th sections were stained. This was done in order to increase the likelihood of capturing incipient neurons with $\alpha$ S-IR inclusions.

\section{Results}

\section{Assessment of clinical data}

The $226 \alpha$ S-positive subjects examined included 114 (50\%) patients with a clinical diagnosis of a neurodegenerative disorder, 15 (7\%) patients with other neurological disorders and $97(43 \%)$ individuals in whom the clinical information indicated that they had no neurological impairment. The mean age at death was $77 \pm 0.6$ years, ranging from 44 to 98 years and the gender was rather evenly distributed (108 females/118 males).
Frequency of $\alpha \mathrm{S}$-immunoreactivity in the most vulnerable anatomical regions

The most frequently affected regions in the $226 \alpha$ S-positive subjects were dmV (197/223) and SN (197/225) where the $\alpha \mathrm{S}-\mathrm{IR}$ was seen in $88 \%$ of the analyzed subjects. The LC was affected in $81 \%(181 / 223)$ of subjects, making this area the second most vulnerable nuclei. The large neurons in the nbM were $\alpha$ S-immunopositive in $78 \%$ of cases (171/219), whereas the involvement of AC, particularly the cortico-medial nuclear group, was seen in 73\% (162/223) of subjects.

Staging of Parkinson disease-related $\alpha \mathrm{S}$ pathology according to Braak and the frequency of dementia and extrapyramidal symptoms

Out of the $226 \alpha$ S-positive subjects, 187 (83\%) displayed a distribution pattern of $\alpha \mathrm{S}$-IR that was compatible with the current staging systems of PD/DLB-related synucleinopathies $[4,28]$. Braak stage 1-2 was applicable for 22 subjects, 3-4 for 38 subjects and 5-6 for 127 subjects (Table 1). When all subjects with severe AD-related neurofibrillary pathology, i.e. Braak's AD stage V-VI, were excluded, 168 cases of the 187 subjects remained. Notably, only $25-30 \%$ of the subjects with PD-related Braak stage 5 and 50\% of subjects with PD-related Braak stage 6 were demented and/or had EPS. It is noteworthy that when only demented subjects were included in the analysis (53 out of 168), 91\% (48/53) were assigned to PD-related Braak stages5-6. Similarly, when only subjects with EPS were included in the analysis (52 out of 168), 94\% (49/52) were in the PD-related Braak stages 5-6.

Categorization of the distribution of $\alpha \mathrm{S}$ pathology following the recommendations by the consortium on DLB international workshop, i.e. McKeith's categorization, and the frequency of dementia and extrapyramidal symptoms

Sixty-six subjects fulfilled Mc Keith's criteria for the brainstem predominant form, 30 for the limbic (transitional) and 91 for the diffuse neocortical form of DLB (Table 2).

Fifty-seven percent of subjects with the diffuse neocortical form of DLB were demented and 47\% displayed EPS (Table 2). When AD-related pathology was taken into account as suggested by McKeith and colleagues [28] (Table 3), the percentage of demented in the high likelihood category varied from 24 to $60 \%$. Irrespective of the $\alpha \mathrm{S}$ pathology, in Braak's AD stage V-VI, all subjects were demented. Notably, when only demented subjects were included in the analysis and the subject with severe AD-related pathology (Braak's AD stage V-VI) were excluded, 85\% (45/53) were assigned to a high likelihood category of DLB. 
Table 1 Applicability of Braak staging and the incidence of dementia and extrapyramidal signs (EPS) in each stage
Table 2 Applicability of neuropathological categorization as recommended by the consortium on DLB international workshop, i.e. McKeiths categorization and the incidence of dementia and extrapyramidal signs (EPS) in each category

\begin{tabular}{|c|c|c|c|c|c|c|}
\hline \multirow{2}{*}{$\begin{array}{l}\text { Distribution of } \alpha S \text {-positive } \\
\text { structures }\end{array}$} & \multicolumn{6}{|c|}{ Parkinson's disease related pathology staged as recommended by Braak } \\
\hline & 1 & 2 & 3 & 4 & 5 & 6 \\
\hline dorsal motor nucleus of vagus & $\mathrm{n}=10$ & & \multirow{3}{*}{$n=16$} & \multirow{4}{*}{$\mathbf{n}=\mathbf{2 2}$} & \multirow{5}{*}{$n=25$} & \multirow{6}{*}{$\mathrm{n}=\mathbf{8 4}$} \\
\hline $\begin{array}{l}\text { locus coeruleus } \\
\text { raphe nucleus }\end{array}$ & & $n=11$ & & & & \\
\hline $\begin{array}{l}\text { substantia nigra } \\
\text { nucleus basalis of Meynert } \\
\text { CA2 region }\end{array}$ & & & & & & \\
\hline $\begin{array}{l}\text { amygdaloid complex } \\
\text { (trans)entorhinal cortex } \\
\text { temporo-occipital gyrus }\end{array}$ & & & & & & \\
\hline $\begin{array}{l}\text { insular cortex } \\
\text { cingulate gyrus } \\
\text { temporal gyrus }\end{array}$ & & & & & & \\
\hline $\begin{array}{l}\text { frontal cortex } \\
\text { parietal cortex }\end{array}$ & & & & & & \\
\hline number with dementia (\%) & $\mathbf{0}(0 \%)$ & $1(9 \%)$ & $\mathbf{0}(0 \%)$ & $4(18 \%)$ & $6(25 \%)$ & $42(50 \%)$ \\
\hline number with EPS (\%) & $\mathbf{0}(0 \%)$ & $1(9 \%)$ & $2(13 \%)$ & $0(0 \%)$ & $7(28 \%)$ & $42(50 \%)$ \\
\hline $\begin{array}{l}\text { number of all cases, i.e. } \\
\text { Braak's AD stages V-VI also } \\
\text { included }\end{array}$ & 10 & 12 & 16 & 22 & 28 & 99 \\
\hline
\end{tabular}

\begin{tabular}{|c|c|c|c|}
\hline \multirow{2}{*}{$\begin{array}{l}\text { Distribution of } \alpha S \text {-positive } \\
\text { structures }\end{array}$} & \multicolumn{3}{|c|}{ Parkinson's disease related pathology categorized as recommended by McKeith and colleagues } \\
\hline & Brainstem predominant & Limbic transitional & Diffuse neocortical \\
\hline $\begin{array}{l}\text { dorsal motor nucleus of vagus } \\
\text { locus coeruleus } \\
\text { raphe nucleus } \\
\text { substantia nigra } \\
\text { nucleus basalis of Meynert } \\
\text { amygdaloid complex } \\
\text { (trans)entorhinal cortex } \\
\text { cingulate gyrus }\end{array}$ & $\mathbf{n}=\mathbf{6 6}$ & \multirow[t]{2}{*}{$\mathbf{n}=\mathbf{3 0}$} & \multirow[t]{3}{*}{$\mathbf{n}=91$} \\
\hline $\begin{array}{l}\text { temporal gyrus } \\
\text { frontal cortex }\end{array}$ & & & \\
\hline parietal cortex & & & \\
\hline number with dementia (\%) & $8(12 \%)$ & $11(37 \%)$ & $52(57 \%)$ \\
\hline number with EPS (\%) & $5(8 \%)$ & $10(33 \%)$ & $43(47 \%)$ \\
\hline
\end{tabular}

Table 3 Assessment of likelihood that the pathological findings are associated with a DLB clinical syndrome

\begin{tabular}{llll}
\hline $\begin{array}{l}\text { Category of Lewy } \\
\text { body type pathology }\end{array}$ & \multicolumn{2}{l}{ Alzheimer type pathology } & \\
\cline { 2 - 4 } & Braak stage 0-II & Braak stage III-IV & Braak stage V-VI \\
\hline Brainstem predominant & Low & Low & Low \\
$n=66$ & $n=58$ & $n=7$ & $n=1$ \\
& 5 demented (9\%) & 2 demented (29\%) & 1 demented (100\%) \\
& 5 with EPS (9\%) & 0 with EPS (0\%) & 0 with EPS (0\%) \\
Limbic transitional & High & Intermediate & Low \\
$n=30$ & $n=25$ & $n=1$ & $n=4$ \\
& 6 demented (24\%) & 1 demented (100\%) & 4 demented (100\%) \\
& 9 with EPS (36\%) & 0 with EPS (0\%) & 1 with EPS (25\%) \\
Diffuse neocortical & High & High & Intermediate \\
$n=91$ & $n=63$ & $n=15$ & $n=13$ \\
& 30 demented (48\%) & 9 demented (60\%) & 13 demented (100\%) \\
& 34 with EPS (54\%) & 4 with EPS (29\%) & 5 with EPS (36\%) \\
\hline
\end{tabular}

Atypical cases i.e. cases that could not be classified as recommended

Thirty-nine cases were not classifiable as recommended and thus were assigned as being atypical i.e. neither Braak staging nor McKeith categorization systems could be applied. The deviating topographical distribution of $\alpha \mathrm{S}$-IR inclusions of these subjects is shown in Table 4. In four subjects, the BFB nuclei (AC predominant) were severely affected (cases 1-4) together with some cortical inclusions, whereas the brainstem had been preserved. Five subjects displayed isolated minor involvement of SN without any $\alpha \mathrm{S}-\mathrm{IR}$ inclusions in the lower brainstem nuclei (cases 5-9). In six subjects (cases 10-15) minor involvement of both SN and BFB nuclei was detected (cases 10-15). In addition to these two areas, three cases exhibited severe $\alpha \mathrm{S}$ pathology in $\mathrm{AC}$ (cases 16-18, AC predominant). In seven subjects, some inclusions were seen in the BFB, SN and LC, but not 
Table 4 Topographic distribution of $\alpha \mathrm{S}$ immunoreactive lesions in the 39 atypical cases, i.e. not classifiable following current recommendations ID Age Sex EPS Dem AD stage Topographical distribution of $\alpha$ S-immunoreactive structures

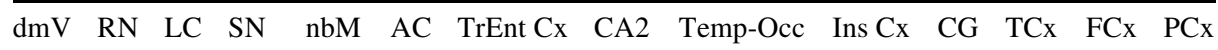

\begin{tabular}{|c|c|c|c|c|c|c|c|c|c|c|c|c|c|c|c|c|c|c|c|}
\hline 1 & 79 & $\mathrm{~F}$ & No & Yes & 4 & 0 & 0 & 0 & 0 & 0 & 4 & 1 & 0 & 0 & 0 & 0 & 0 & 0 & 0 \\
\hline 2 & 62 & $\mathrm{~F}$ & No & Yes & 6 & 0 & 0 & 0 & 0 & 0 & 4 & 2 & 0 & 1 & 0 & 0 & 0 & 0 & 0 \\
\hline 3 & 74 & $\mathrm{~F}$ & No & Yes & 2 & 0 & 0 & 0 & 0 & + & 4 & 2 & 0 & 2 & 0 & 1 & 1 & 0 & 0 \\
\hline 4 & 79 & $\mathrm{~F}$ & Yes & Yes & 6 & 0 & 0 & 0 & 0 & + & 3 & 0 & 0 & 0 & 1 & 1 & 1 & 0 & 0 \\
\hline 5 & 86 & $\mathrm{~F}$ & No & No & 4 & 0 & 0 & 0 & + & 0 & 0 & 0 & 0 & 0 & 0 & 0 & 0 & 0 & 0 \\
\hline 6 & 44 & $\mathrm{M}$ & No & No & 0 & 0 & 0 & 0 & + & 0 & 0 & 0 & 0 & 0 & 0 & 0 & 0 & 0 & 0 \\
\hline 7 & 68 & $\mathrm{M}$ & No & No & 1 & 0 & 0 & 0 & + & 0 & 0 & 0 & 0 & 0 & 0 & 0 & 0 & 0 & 0 \\
\hline 8 & 83 & $\mathrm{M}$ & No & No & 2 & 0 & 0 & 0 & + & 0 & 0 & 0 & 0 & 0 & 0 & 0 & 1 & 0 & 0 \\
\hline 9 & 83 & $\mathrm{M}$ & No & No & 1 & 0 & + & 0 & + & 0 & 0 & 0 & 0 & 0 & 0 & 0 & 0 & 0 & 0 \\
\hline 10 & 75 & $\mathrm{~F}$ & No & No & 0 & 0 & 0 & 0 & + & + & 0 & 0 & 0 & 0 & 0 & 0 & 0 & 0 & 0 \\
\hline 11 & 76 & $\mathrm{M}$ & No & No & 1 & 0 & 0 & 0 & + & + & 0 & 0 & 0 & 0 & 0 & 0 & 2 & 0 & 0 \\
\hline 12 & 70 & $\mathrm{M}$ & No & No & 0 & 0 & 0 & 0 & + & + & 0 & 0 & 0 & 0 & 0 & 0 & 0 & 0 & 0 \\
\hline 13 & 77 & $\mathrm{~F}$ & No & No & 2 & 0 & 0 & 0 & + & + & 2 & 1 & 0 & 0 & 0 & 0 & 0 & 0 & 0 \\
\hline 14 & 73 & $\mathrm{M}$ & Yes & Yes & 2 & 0 & 0 & 0 & ++ & + & 0 & 0 & 0 & 0 & 0 & 0 & 1 & 0 & 0 \\
\hline 15 & 71 & $\mathrm{~F}$ & No & Yes & 6 & 0 & 0 & 0 & +++ & + & 0 & 0 & 0 & 1 & 1 & 1 & 1 & 0 & 0 \\
\hline 16 & 79 & $\mathrm{~F}$ & No & Yes & 5 & 0 & 0 & 0 & + & 0 & 3 & 3 & 0 & 0 & 1 & 0 & 0 & 0 & 0 \\
\hline 17 & 87 & $\mathrm{~F}$ & No & Yes & 2 & 0 & 0 & 0 & + & + & 4 & na & na & 0 & 0 & 0 & 0 & 0 & 0 \\
\hline 18 & 74 & $\mathrm{~F}$ & No & Yes & 6 & 0 & 0 & 0 & + & na & 4 & na & + & 1 & 0 & 0 & 0 & 0 & 0 \\
\hline 19 & 62 & $\mathrm{M}$ & Yes & Yes & 0 & 0 & 0 & + & + & 0 & 0 & 0 & 0 & 0 & 0 & 0 & 0 & 0 & 0 \\
\hline 20 & 79 & $\mathrm{M}$ & No & Yes & 0 & 0 & 0 & + & + & + & 0 & 0 & 0 & 0 & 0 & 0 & 0 & 0 & 0 \\
\hline 21 & 84 & $\mathrm{~F}$ & No & Yes & 2 & 0 & 0 & + & + & ++ & 0 & 0 & 0 & 0 & 0 & 0 & 0 & 0 & 0 \\
\hline 22 & 85 & $\mathrm{~F}$ & No & No & 0 & 0 & 0 & + & + & + & 1 & 1 & na & na & 0 & 0 & 0 & 0 & 0 \\
\hline 23 & 82 & $\mathrm{~F}$ & No & Yes & 3 & 0 & 0 & + & + & ++ & na & 2 & 0 & 0 & 1 & 0 & 0 & 0 & 0 \\
\hline 24 & 58 & $\mathrm{M}$ & No & No & 0 & 0 & 0 & + & +++ & ++ & 0 & 0 & 0 & 0 & 0 & 0 & 0 & 0 & 0 \\
\hline 25 & 84 & $\mathrm{M}$ & No & No & 3 & 0 & 0 & + & +++ & + & 3 & 2 & 0 & 1 & 0 & 2 & 0 & 0 & 0 \\
\hline 26 & 76 & $\mathrm{M}$ & No & No & 1 & + & 0 & 0 & + & 0 & 0 & 0 & 0 & 0 & 0 & 0 & 0 & 0 & 0 \\
\hline 27 & 87 & $\mathrm{~F}$ & No & No & 1 & + & 0 & 0 & + & + & 0 & 0 & 0 & 0 & na & 0 & 0 & 0 & 0 \\
\hline 28 & 78 & $\mathrm{M}$ & No & No & 1 & + & 0 & 0 & + & + & 2 & 2 & 0 & 0 & 0 & 0 & 0 & 0 & 0 \\
\hline 29 & 84 & $\mathrm{~F}$ & No & Yes & 5 & + & 0 & 0 & + & 0 & 1 & na & + & 1 & 0 & 0 & 0 & 0 & 0 \\
\hline 30 & 75 & $\mathrm{~F}$ & Yes & Yes & 5 & ++ & 0 & 0 & + & 0 & 1 & 0 & 0 & 0 & 0 & 0 & 0 & 0 & 0 \\
\hline 31 & 60 & $\mathrm{~F}$ & No & No & 0 & +++ & 0 & 0 & + & 0 & 0 & 0 & 0 & 0 & 0 & 0 & 0 & 0 & 0 \\
\hline 32 & 80 & $\mathrm{M}$ & No & Yes & 6 & + & 0 & 0 & ++ & 0 & 0 & 0 & 0 & 0 & 0 & 1 & 0 & 0 & 0 \\
\hline 33 & 69 & $\mathrm{M}$ & No & No & 1 & ++ & + & 0 & ++ & ++ & 1 & 1 & 0 & 0 & 0 & 1 & 0 & 0 & 0 \\
\hline 34 & 80 & $\mathrm{M}$ & Yes & Yes & 5 & ++ & 0 & 0 & ++ & + & 3 & 2 & + & 1 & 1 & 1 & 0 & 0 & 0 \\
\hline 35 & 86 & $\mathrm{~F}$ & No & Yes & 6 & + & + & 0 & + & 0 & 4 & 4 & + & 3 & 0 & 0 & 1 & 0 & 0 \\
\hline 36 & 64 & $\mathrm{~F}$ & No & Yes & 6 & + & 0 & 0 & + & na & 4 & na & + & na & 0 & 0 & 1 & 0 & 0 \\
\hline 37 & 74 & $\mathrm{~F}$ & No & Yes & 6 & + & 0 & 0 & + & + & 4 & 4 & 0 & na & 0 & 1 & 2 & 0 & 0 \\
\hline 38 & 78 & $\mathrm{M}$ & No & Yes & 5 & + & 0 & 0 & + & + & 3 & 3 & + & 1 & 2 & 1 & 1 & 0 & 0 \\
\hline 39 & 89 & M & No & No & 2 & + & 0 & 0 & + & + & 2 & 2 & 0 & 0 & 0 & 1 & 1 & 1 & 0 \\
\hline
\end{tabular}

EPS extrapyramidal signs, Dem clinical signs of dementia, AD stage the stage of Alzheimer's disease related neurofibrillary pathology stages as recommended by Braak from 0 to VI., $d m V$ dorsal motor nucleus of vagus, $R N$ raphe nucleus, $L C$ locus coeruleus, $S N$ substantia nigra, $n b M$ nucleus basalis of Meynert, $A C$ amygdaloid complex, TrEntCx transentorhinal cortex, CA2 CA2 region of the Cornu Ammonis of the hippocampus, Temp$O c c$ temporo-occipital gyrus, Ins $C x$ insular cortex, $C G$ cingulate gyrus, $T C x$ temporal cortex, $F C x$ frontal cortex, $P C x$ parietal cortex; $n a$ not available. The $\alpha \mathrm{S}$-immunoreactive inclusions were examined in the total thickness of the cortical grey matter and AC and rated as follows: 1 mild (sparse inclusions in $\times 100$ ), 2 moderate ( $>1$ inclusion in $\times 200$ magnification), 3 severe ( $\geq 4$ inclusions in $\times 200$ magnification), 4 very severe (numerous inclusions), in the $\mathrm{nbM}$ and subcortical regions, $\alpha \mathrm{S}$ - immunoreactive inclusions were counted unilaterally within entire nuclei and assessed following an arbitrary grading system: in $\mathrm{nbM}$ and $\mathrm{SN},+$ mild ( $<25$ inclusions), ++ moderate ( $25-50$ inclusions), +++ severe ( $>50$ inclusions), and in $\mathrm{LC}$ and $\mathrm{dmV},+$ mild (1-2 inclusions), ++ moderate (2-10 inclusion), +++ severe ( $>10$ inclusions). In Raphe nucleus and CA2 region of the hippocampus, $\alpha \mathrm{S}$-immunoreactive structures (inclusion and/or neurites) were marked to be present $(+)$ or not $(0)$ 
in the $\mathrm{dmV}$ (cases 19-25). In the final 14 subjects (cases 26-39), inclusions were seen in the $\mathrm{dmV}$ and $\mathrm{SN}$, but not in the LC, together with variable affection of BFB and other cortical regions. In only minority of these cases EPS symptoms were seen $(13 \%)$, whereas dementia was more common (54\%). In 14 cases dementia was due to AD-related neurofibrillary pathology (Braak stage V-VI), in six cases numerous multifocal microscopic infarcts and concomitant severe white matter rarefaction was considered as the causative agent regarding dementia and in one cases neuropathological lesions consistent with frontotemporal dementia with ubiquitin only lesions were seen.

\section{Discussion}

Most of our (83\%) $\alpha \mathrm{S}$-positive cases could be assigned to one of the six PD stages as described by Braak and also into the brainstem, limbic or diffuse neocortical neuropathological category as recommended by McKeith and colleagues $[4,28]$. Braak and colleagues depicted the topographical distribution of $\alpha \mathrm{S}$-IR structures by assessing $110 \alpha \mathrm{S}$-positive subjects (69 incidental and 41 symptomatic PD patients) [4]. The initial intent of Braak and colleagues was not to correlate the designated neuropathological stages with clinical symptoms, however this was later contemplated [5]. Stages 1 and 2, i.e. stages where $\alpha \mathrm{S}$ pathology is confined to the $\mathrm{dmV}$ and/or LC, are considered to be presymptomatic, whereas EPS appear and the cognitive decline increases with each stage. In stage 3 , when $\mathrm{SN}$ is affected, EPS appear and subsequently in stage 4 when amygdaloid complex, transentorhinal region and temporooccipital gyrus become involved, moderate cognitive impairment is observed (MMSE scores 21-24) and finally in stage 5 and 6 when the neocortex succumbs to the pathology, severe cognitive impairment is evident (MMSE scores $11-20$ and 0-10, respectively) [5]. Our results also suggest that the risk of EPS increases with disease progression though not to the same extent as earlier reported. In our study, we found one subject with EPS already in stage 2 , whereas none of our cases in stage 4 displayed EPS, and more importantly no EPS had been reported in $55 \%$ of subjects who exhibited widespread pathology (Braak stages 5$6)$, i.e. this being compared with the $14 \%$ previously reported by Braak and colleagues [4].

The initial decline in cognition was postulated to occur already during stages 3 and 4 i.e. around the same time when the initial manifestation of somatosensor dysfunction start to appear. When assessing 88 subjects, Braak and colleagues reported, that $36 \%$ of their subjects in stage $3,67 \%$ in stage $4,94 \%$ in stage 5 and $100 \%$ in stage 6 were demented [5]. This is clearly in odds with our results where the percentage of demented increased from none to $50 \%$ between stages 3-6. It is noteworthy that when only demented subjects were included, $91 \%$ were assigned to PD-related Braak stages 5-6 and when only subjects with EPS were included, 94\% were in the PD-related Braak stages 5-6. Thus the key difference between our study when compared to most other clinico-pathological correlation studies that have reported good correlation between risk of disease and progression of pathology is the study design [5]. Consequently, when we only included subjects with clinical signs in our analysis the correlation between stage/ severity of $\alpha \mathrm{S}$ pathology and EPS/dementia was excellent in line with previous reports.

PD and DLB are distinguished as separate clinical entities and in 1996 the consortium of the DLB international workshop subdivided the neuropathological features of DLB into three categories: brainstem predominant, limbic and diffuse neocortical type [27]. The foundation of these three categories is also based on the progressive propagation of $\alpha \mathrm{S}$ pathology along a caudo-striatal axis. Similarly to the Braak staging [4], when applying this categorization it is presumed that $100 \%$ of subjects with widespread $\alpha \mathrm{S}$ pathology, i.e. in the diffuse neocortical stage all will be demented and display EPS. When we followed the classification strategy proposed by McKeith and colleagues [28], our results also differed from those expected, i.e. only a subset of our subjects who were classified to be in the diffuse neocortical category displayed dementia and/or EPS (57 and $47 \%$, respectively). In line with the above, when only demented subjects were included in the analysis the correlation between $\alpha \mathrm{S}$ pathology and dementia was close to excellent $(85 \%)$.

The clinical relevance of cortical $\alpha \mathrm{S}$ pathology in relation to dementia is a matter of intense debate. Some authors have emphasized their key causative role $[1,18,21,26]$, whereas others have reported that there may be abundant cortical pathology in non-demented PD patients [8] as well as in neurologically unimpaired subjects $[10,24,32]$. It is noteworthy that the current study differs significantly from most other studies since it is based on neuropathologiacal findings rather than on clinical presentation. Our results emphasize that abundant pathology may be detected in many subjects without notable signs of dementia (MMSE $>26)(43 \%)$, if it is sought. This has one unexpected consequence, i.e. a detailed regional assessment of $\alpha \mathrm{S}$ pathology cannot reliably predict the clinical status observed premortem [33].

There has been much discussion concerning the significance and influence of concomitant AD-related pathology, particularly as this is quite frequently seen in aged subjects. Therefore, the revised consensus criteria have recommended taking AD-related pathology into account while assessing subjects with suspected DLB [28]. It was presumed that this would increase the diagnostic specificity 
since it was believed that the pathological substrate behind DLB was indeed $\alpha \mathrm{S}$ pathology. When we assessed our unique material, we found, that within the neuropathological high likelihood categories of DLB, i.e. those cases where limbic/diffuse neocortical $\alpha \mathrm{S}$ pathology is combined with mild/moderate AD-related changes, $56 \%$ of subjects remained cognitively intact. However, when we examined only demented subjects without severe AD-related pathology (Braak's AD stage V-VI), $85 \%$ were assigned to a high likelihood category of DLB. This shows that when $\alpha \mathrm{S}$ pathology is examined in clinically demented subjects, the correlation received between particular pathologic change and dementia is good. It is noteworthy that with respect of AD-related neurofibrillary pathology, all cases in the neocortical stage (Braak stage V-VI) were indeed demented.

One important issue with respect to the pathogenesis of synucleinopathies is not only to understand the molecular mechanisms behind the intracytoplasmic aggregation of $\alpha \mathrm{S}$, but also to appreciate where this process first appears and how it may progress through the brain. Thus, many recent studies have attempted to localize the most vulnerable neuronal populations. In this study, $\mathrm{dmV}$ and $\mathrm{SN}$ were found to be equally susceptible nuclei, but even earlier affected structures have been reported to appear in the spinal cord, $\mathrm{dmV}$, olfactory bulb and AC $[2,4,11,16,22,35]$. Thus, mapping out the "trigger site" for $\alpha \mathrm{S}$ pathology appears to depend on the screening process i.e. if one screens medulla alone, those cases where lesions are restricted to other areas (e.g. SN) are not found and vice versa.

At variance to the studies of Del Tredici and Braak [4, 11] we identified a number of subjects where $\mathrm{dmV}$ and/or LC were not affected but $\alpha \mathrm{S}$-IR inclusions were found in the SN, BFB and or other cortical regions, and thus, the distribution of $\alpha \mathrm{S}$ pathology did not strictly follow the caudo-rostral propagation pattern described by Braak and colleagues [4]. Thus, the proposed ascending pathway is not the only possible route and our results indicate that pathology can emerge simultaneously in subcortical and cortical regions. Jellinger has also reported subjects with multiple $\alpha \mathrm{S}$-IR inclusions but with preservation of medullary nuclei [20]. Furthermore, in some subjects we found the $\mathrm{AC}$ to be devoid of pathology although $\alpha \mathrm{S}$-IR structures were detected elsewhere in the neocortex. This refutes the proposal that in order to have neocortical involvement then the subcortical lesions have to expand through the basal forebrain nuclei. In addition, according to Braak and colleagues [4], the $\alpha \mathrm{S}$ pathology in previously involved regions should become exacerbated with disease progression. It is difficult to evaluate this proposal when one takes into account the increasing neuronal loss. If these two pathological hallmarks are linked in a causative chain, the load of $\alpha \mathrm{S}$-IR structures should show an inverted u-shape distribution over time where the number of inclusions would increases with the progression of the disease until the neurons start to die [12].

We observed some cases with severe $\alpha \mathrm{S}$ pathology in $\mathrm{AC}$ and in that situation this structure was either only involved region or was affected together with BFB and SN. All these subjects were demented and exhibited coexistent severe AD-related pathology (Braak AD stage V-VI [6]). In one case, the dementia was considered to be vascular in origin. This is in line with the results of Uchikado and colleagues who have reported the AC predominant form to be common finding among patients with $\mathrm{AD}$ [35].

In conclusion, our results confirm that the current staging/categorization systems can readily be applied to most of the subjects when assessing regional distribution of $\alpha \mathrm{S}$ pathology. It is noteworthy, however, that outliers do exist and in these cases the presumed distribution may have been modified by other coexisting pathologies or genetic factors $[23,35]$. It is intriguing that around every second subject displaying abundant pathology did remain neurologically intact. It is noteworthy that these results were seen when a rather unselected sample of cases was investigated. It has been suggested that the key lesions begin to develop a considerable time prior to the appearance of clinical symptoms [13], but based on our results there do seem to be some subjects who can tolerate substantial amounts of pathology. As only $50 \%$ of subjects with widespread $\alpha \mathrm{S}$ pathology were demented (MMSE <26) and displayed EPS, the clinical relevance of $\alpha \mathrm{S}$-IR inclusions as such still remains to be resolved. Hitherto, the aggregation of $\alpha \mathrm{S}$ has been thought to lead to neuronal death but recent evidence has suggested that the formation of large inclusions may actually represent a protective process [3, 14, 34]. Many biophysical studies have suggested that it is a protofibrillar form of $\alpha \mathrm{S}$ rather than the "mature" fibrils that are responsible for the cell death [7, 15, 36], and moreover, the fibrillar form that is typically observed at autopsy may actually be a sign of a well functioning neuroprotection [31,34]. Thus, when we are assessing regional distribution of $\alpha \mathrm{S}$ pathology, the question arises if we are really evaluating a stage of degeneration or conversely monitoring the level of functional neuroprotection.

Acknowledgments We thank medical laboratory technologist Tarja Kauppinen and Mrs. Marja Fali, Mr. Heikki Luukkonen and Mr. Hannu Tiainen for their skilful technical assistance. This study was supported by European Union EU grant LSHM-CT-2006-037050. The study has been authorized by the Ethics Committee of Kuopio University Hospital.

\section{References}

1. Apaydin H, Ahlskog JE, Parisi JE, Boeve BF, Dickson DW (2002) Parkinson disease neuropathology: later-developing dementia and loss of the levodopa response. Arch Neurol 59:102-112 
2. Bloch A, Probst A, Bissig H, Adams H, Tolnay M (2006) Alphasynuclein pathology of the spinal cord and peripheral autonomic nervous system in neurologically unimpaired elderly. Neuropathol Appl Neurobiol 32:284-295

3. Bodner RA, Outeiro TF, Altmann A, Maxwell MM, Cho SH, Hyman BT, Mc Lean PJ, young AB, Housman DE, Kazantsev AG (2007) Pharmacological promotion of inclusion formation: a therapeutic approach fro Huntington's and Parkinson's diseases. PNAS 14(103):4246-4251

4. Braak H, Del Tredici K, Rub U, de Vos RA, Jansen Steur EN, Braak E (2003) Staging of brain pathology related to sporadic Parkinson's disease. Neurobiol Aging 24:197-211

5. Braak H, Rub U, Del Tredici K, Jansen Steur EN, de Vos RA (2005) Cognitive status with neuropathologic stage in Parkinson disease. Neurology 64:1404-1410

6. Braak H, Alafuzoff I, Arzberger T, Kretzschmar H, Del Tredici K (2006) Staging of Alzheimer disease-associated neurofibrillary pathology using paraffin sections and immunocytochemistry. Acta Neuropathol 112(4):389-404

7. Caughey B, Lansbury PT (2003) Protofibrils, pores, fibrils and neurodegeneration: separating the responsible protein aggregates from innocent bystanders. Annu Rev Neurosci 26:267-298

8. Colosimo C, Hughes AJ, Kilford L, Lees AJ (2003) Lewy body cortical involvement may not always predict dementia in Parkinson's disease. J Neurol Neurosurg Psychiatry 74:852-856

9. Daniel SE, Lees AJ (1993) Parkinson's Disease Society Brain Bank, London: overview and research. J Neural Transm Suppl 39:165

10. Davis DG, Schmitt FA, Wekstein DR, Markesbery WR (1999) Alzheimer neuropathologic alterations in aged cognitively normal subjects/1999). J Neuropathol Exxp neurol 58(4):376-388

11. Del Tredici K, Rub U, De Vos RA, Bohl JR, Braak H (2002) Where does parkinson disease pathology begin in the brain? J Neuropathol Exp Neurol 61:413-426

12. Duda JE (2004) Pathology and neurotransmitter abnormalities of dementia with lewy bodies. Dement Geriatr Cogn Disord 17: 3-14

13. Fearnley JM, Lees AJ (1991) Ageing and Parkinson's disease: substantia nigra regional selectivity. Brain 114:2283-2301

14. Garske AL, Smith BC, Denu JM (2007) Linking sirt2 to Parkinson's disease. ACS Chem Biol 2(8):529-532

15. Goldberg MS, Lansbury PT Jr (2000) Is there a cause-and-effect relationship between alpha-synuclein fibrillization and Parkinson's disease? Nat Cell Biol 2:E115-E119

16. Hamilton RL (2000) Lewy bodies in Alzheimer's disease: a neuropathological review of 145 cases using alpha-synuclein immunohistochemistry. Brain Pathol 10:378-384

17. Hishikawa N, Hashizume Y, Yoshida M, Sobue G (2003) Clinical and neuropathological correlates of Lewy body disease. Acta Neuropathol 105:341-350

18. Hurtig HI, Trojanowski JQ, Galvin J, Ewbank D, Schmidt ML, Lee VM, Clark CM, Glosser G, Stern MB, Gollomp SM, Arnold SE (2000) Alpha-synuclein cortical Lewy bodies correlate with dementia in Parkinson's disease. Neurology 54:1916-1921

19. Ince PG, Perry EK, Morris CM (1998) Dementia with Lewy bodies. A distinct non-Alzheimer dementia syndrome? Brain Pathol 8:299-324

20. Jellinger KA (2003) Alpha-synuclein pathology in Parkinson's and Alzheimer's disease brain: incidence and topographic distribution-a pilot study. Acta Neuropathol 106:191-201

21. Kovari E, Gold G, Herrmann FR, Canuto A, Hof PR, Bouras C, Giannakopoulos P (2003) Lewy body densities in the entorhinal and anterior cingulate cortex predict cognitive deficits in Parkinson's disease. Acta Neuropathol 106:83-88

22. Klos KJ, Ahlskog JE, Josephs KA, Apaydin H, Parisi JE, Boeve BF, DeLucia MW, Dickson DW (2006) Alpha-synuclein pathology in the spinal cords of neurologically asymptomatic aged individuals. Neurology 66:1100-1102
23. Klunk WE, Price JC, Mathis CA, Tsopelas ND, Lopresti BJ, Ziolko SK, Bi W, Hoge JA, Cohen AD, Ikonomovic MD, Saxton JA, Snitz BE, Pollen DA, Moonis M, Lippa CF, Swearer JM, Johnson KA, Rentz DM, Fischman AJ, Aizenstein HJ, DeKosky ST (2007). Amyloid deposition begins in the striatum of presenilin-1 mutation carriers from two unrelated pedigrees. J Neurosci 27(23):6174-6184

24. Knopman DS, Parisi JE, Salviati A, Floriach-Robert M. Boeve BF, Ivnik RJ, Smith GE, Dickson DW, Johnson KA, Petersen LE, McDonald WC, Braak H, Petersen RC (2003) Neuropathology of cognitively normal elderly. J Neuropathol Exp Neurol 62(11):1087-1095

25. Kosaka K, Yoshimura M, Ikeda K, Budka H (1984) Diffuse type of Lewy body disease: progressive dementia with abundant cortical Lewy bodies and senile changes of varying degree-a new disease? Clin Neuropathol 3:185-192

26. Mattila PM, Rinne JO, Helenius H, Dickson DW, Roytta M (2000) Alpha-synuclein-immunoreactive cortical Lewy bodies are associated with cognitive impairment in Parkinson's disease. Acta Neuropathol 100:285-290

27. McKeith IG, Galasko D, Kosaka K, Perry EK, Dickson DW, Hansen LA, Salmon DP, Lowe J, Mirra SS, Byrne EJ, Lennox G, Quinn NP, Edwardson JA, Ince PG, Bergeron C, Burns A, Miller BL, Miller BL, Lovestone S, Collerton D, Jansen EN, Ballard C, de Vos RA, Wilcock GK, Jellinger KA, Perry RH (1996) Consensus guidelines for the clinical and pathologic diagnosis of dementia with Lewy bodies (DLB): report of the consortium on DLB international workshop. Neurology 47:1113-1124

28. McKeith IG, Dickson DW, Lowe J, Emre M, O'Brien JT, Feldman H, Cummings J, Duda JE, Lippa C, Perry EK, Aarsland D, Arai H, Ballard CG, Boeve B, Burn DJ, Costa D, Del Ser T, Dubois B, Galasko D, Gauthier S, Goetz CG, Gomez-Tortosa E, Halliday G, Hansen LA, Hardy J, Iwatsubo T, Kalaria RN, Kaufer D, Kenny RA, Korczyn A, Kosaka K, Lee VM, Lees A, Litvan I, Londos E, Lopez OL, Minoshima S, Mizuno Y, Molina JA, MukaetovaLadinska EB, Pasquier F, Perry RH, Schulz JB, Trojanowski JQ, Yamada M; Consortium on DLB (2005) Diagnosis and management of dementia with Lewy bodies: third report of the DLB consortium. Neurology 65(12):1863-1872

29. McKhann G, Drachman D, Folstein M, Katzman R, Price D, Stadlan EM (1984) Clinical diagnosis of Alzheimer's disease: report of the NINCDS-ADRDA Work Group under the auspices of Department of Health and Human Services Task Force on Alzheimer's disease. Neurology 34:939-944

30. Olanow CW, Perl DP, DeMartino GN, McNaught KS (2004) Lewy-body formation is an aggresome-related process: a hypothesis. Lancet Neurol 3:496-503

31. Outeiro TF, Kontopoulos E, Altmann SM, Kufareva I, Strathearn KE, Amore AM, Volk CB, Maxwell MM, Rochet J-C, McLean PJ, Young AB,Abagyan R, Feany MB, Hyman BT, Kazantsev AG (2007) Sirtuin 2 inhibitors rescue $\alpha$-synuclein-mediated toxicity in models of Parkinson's disease. Science 317(5837):516-519

32. Parkkinen L, Pirttila T, Tervahauta M, Alafuzoff I (2005) Widespread and abundant alpha-synuclein pathology in a neurologically unimpaired subject. Neuropathology 25:304-314

33. Parkkinen L, Kauppinen T, Pirttila T, Autere JM, Alafuzoff I (2005) Alpha-synuclein pathology does not predict extrapyramidal symtptoms or dementia. Ann Neurol 57:82-91

34. Tanaka M, Kim YM, Lee G, Junn E, Iwatsubu T, Mouradian MM (2004) Aggresomes formed by alpha-synuclein and synphilin-1 are cytoprotective. J Biol Chem 279:4625-4631

35. Uchikado H, Lin WL, DeLucia MW, Dickson DW (2006) Alzheimer disease with amygdala Lewy bodies: a distinct form of alphasynucleinopathy. J Neuropathol Exp Neurol 65(7):685-697

36. Volles MJ, Lansbury PT Jr (2003) Zeroing in on the pathogenic form of alpha-synuclein and its mechanism of neurotoxicity in Parkinson's disease. Biochemistry 42:7871-7878 